\title{
RADIO FREQUENCY OPTIMIZATION OF MOBILE NETWORKS IN ABEOKUTA, NIGERIA FOR IMPROVED QUALITY OF SERVICE
}

\author{
Olasunkanmi F. Oseni ${ }^{1}$, Segun I. Popoola ${ }^{2}$, Henry Enumah ${ }^{3}$, Ayonote Gordian ${ }^{4}$ \\ ${ }^{1}$ Lecturer, Department of Electronic and Electrical Engineering, Ladoke Akintola University of Technology, P.M.B \\ 4000, Ogbomoso, Oyo State, Nigeria. \\ ${ }^{2}$ B.Tech, Department of Electronic and Electrical Engineering, Ladoke Akintola University of Technology, P.M.B \\ 4000, Ogbomoso, Oyo State, Nigeria. \\ ${ }^{3}$ Project Manager, Wireless Communications, Alcatel-Lucent, Nigeria \\ ${ }^{4}$ Technical Manager, Spectrum Communications Services Ltd, Lagos State, Nigeria
}

\begin{abstract}
Radio Frequency Optimization is an important process in verifying and monitoring the performance of any GSM radio network already deployed in an area. It is a periodic activity that is done to maintain a good radio quality of service and enhance end users' perception. This research work aimed at improving the Quality of Service (QoS) of the GSM radio network deployed within Abeokuta City, Nigeria in order to retain existing subscribers and attract new ones while continually expanding the network. A drive test was carried out in dedicated mode with the goal of collecting measurement data as a function of location and to identify the eventual black spots in the GSM radio network. The data collected were analysed in post-processing software tool (MapInfo Professional) to identify the causes of problems and determine how these problems can be solved effectively and efficiently. Poor network coverage and degradation in QoS were encountered in some parts of the city. This performance was due to the land topology and the presence of physical obstructions in the propagation environment. The Hand-Over (HO) failures were mainly due to Base Station Controller (BSC) synchronization issue. Therefore, additional Base Stations were planned to be deployed in those areas; and the BSC synchronization issue was resolved. This will resolve frequent network complaints that lead to customers' dissatisfaction and boost the revenue of the mobile network provider.
\end{abstract}

Keywords: Radio Network Optimization, QoS, Speech Quality Index, Drive Test

\section{INTRODUCTION}

The Nigerian telecommunications industry is rapidly growing and many operators and their operations put forth different services, but in the diverse services provided most of the subscribers do not receive satisfaction due to the poor nature of services available on these networks. Competition in the industry is a likely tool that would indirectly improve services rendered, but this is not yet the case in Nigeria since competition in the telecommunications industry is fairly new and may be described as being inefficient. Hence, there has been a persistent outcry in the media and series of complaints from the National Assembly on the poor performance of mobile telecommunication networks in Nigeria [1].

With the rapid growth of the wireless industry, GSM (Global System for Mobile communications) networks are rolling out and expanding at a high rate. The industry is also becoming intensely competitive. In this environment, high quality of service is a competitive advantage for a service provider. A lot of effort is made by a network operator to monitor the networks and maintain current, comprehensive and accurate status of its quality. This status, together with new traffic demand data is used by the operators to improve their network and adjust its operation [2].
Quality of Service (QoS) of mobile cellular networks which was defined by ITU-T Rec E.800 [3] as "the collective effect of service performance that determine the degree of satisfaction of a user of the service" has many performance attributes or metrics which have continue to give telecommunication experts and operators lot of keen considerations for continual optimality [4]. QoS measurements are essential for quality assurance and benchmarking though they are carried out at high effort and costs [5].

\subsection{Radio Network Optimization}

Optimization involves monitoring, verifying and improving the performance of the radio network. The radio network must be continuously monitored and corrected. The optimization process should be on-going to increase the efficiency of the network leading to revenue generation from the network [6]. To cater for the increasing subscribers' demand, RF optimization teams must ensure minimum blocking/congestion over air interface in order to provide better QoS to guarantee significant network performance [7].

GSM network performance and QoS evaluation are the most important steps for the mobile operators as the revenue and customer satisfaction is directly related to network performance and quality. Radio frequency Network 
Optimization (RNO) teams play a very significant and vital role in optimizing an operational network to meet the everincreasing demands from the end users [8].

Cellular network operators must periodically optimize their networks to accommodate traffic growth and performance degradation. Optimization action after service rollout is to correct the expected errors in network planning and the benefits like improved network capacity, enhanced coverage and quality of service [9].

\subsection{Drive Test Investigation Approach}

Drive tests are the most common measurement tool used by radio network operators to probe the quality status and solve network problems. Drive Testing is a method of measuring and assessing the coverage, capacity and Quality of Service (QoS) of a mobile radio network [2]. It is conducted for checking the coverage criteria of the cell site with the RF drive test tool. The data collected by drive test tool in form of $\log$ files are assessed to evaluate the various RF parameters of the network. The technique consists of using a motor vehicle containing mobile radio network air interface measurement equipment that can detect and record a wide variety of the physical and virtual parameters of mobile cellular service in a given geographical area [10].

Field measurement and network assessment are usually done through drive testing over the coverage area of respective base stations under observation. The data set collected can include information such as [11]: signal intensity; signal quality; interference; dropped calls; blocked calls; call statistics; service level statistics; Quality of Service (QoS) information; handover information; neighbouring cell information and; GPS location co-ordinates.

\subsection{Review of Related Works}

Popoola et al (2009) evaluated the network performance and quality of service (QoS) of GSM cellular system in Nigeria using Key Performance Indicators (KPIs). The result of the study shows that the QoS of GSM system in the country is unreliable [12]. Agajo et al (2012) optimized GSM network performance by developing a pilot study. Simulations were carried out to assess various parameters and recommendations were made on how to improve on the efficiency of the wireless communication network [9].

An evaluation and optimization of Quality of Service (QoS) of Mobile Cellular Networks in Nigeria was carried out in [13] using drive test. With this, a holistic Network Optimization model using an Adaptive Network-Based Fuzzy Inference System (ANFIS) algorithm was developed. Idigo et al in [1] investigated and analysed the quality of service offered by Visafone mobile cellular network in Nigeria using some Network Key Performance Indicators (KPI) namely: Call Setup Success Ratio (CSSR), Call Drop Ratio (CDR) and Traffic Channel (TCH) Congestion Ratio measurements while showing some variations in their results.
Ugwoke et al (2014) carried out an investigation on QoS status in Nigeria while leveraging software engineering concepts to develop an optimization drive test plant for improving QoS thresholds by service providers [14]. The research work in [15] analysed QoS and identified the areas on the GSM network where congestion occurred, the causes of congestion on GSM network and presented a congestion comparative analysis on each of the GSM networks in Nigeria using MTN, CELTEL (Formerly ECONET), GLOBACOM, and MTEL.

Shoewu et al (2011) in [16] presented a report on the quality of service of network optimization and evaluation of Key Performance Indices provided by GSM operators considering the ability to establish and maintain call connections, call retention, handover, inter and intra network call set-up. The work consequently developed a model of service quality and a set of dimensions for comparative evaluation which was opined to direct regulators and service providers.

In this research work, a drive test was carried out in dedicated mode with the goal of collecting measurement data as a function of location and to identify the eventual black spots in the GSM radio network deployed in Abeokuta. The data collected were analysed in postprocessing software tools to identify the causes of problems and determine how these problems can be solved effectively and efficiently. This will thereby improve the radio QOS in Abeokuta. This is a periodic activity aiming to maintain a good radio quality of service and end users perception. The goals are to improve quality of service, retain existing subscribers and attract new ones while continually expanding the network.

\section{MATERIALS AND METHODS}

\subsection{Geographic Description of the Coverage Area}

Abeokuta is situated at $7^{\circ} 9^{\prime} 39^{\prime \prime} \mathrm{N}$ Latitude, $3^{\circ} 20^{\prime} 54^{\prime \prime} \mathrm{E}$ Longitude and 67 metres elevation above the sea level. It is the largest city and capital of Ogun State in South-Western region of Nigeria. It is situated on the east bank of the Ogun River, near a group of rocky outcrops in a wooded savannah [17]. As of 2005, Abeokuta and the surrounding area had a population of 593,140. Figure 1 shows the propagation environment of the mobile radio network investigated. 


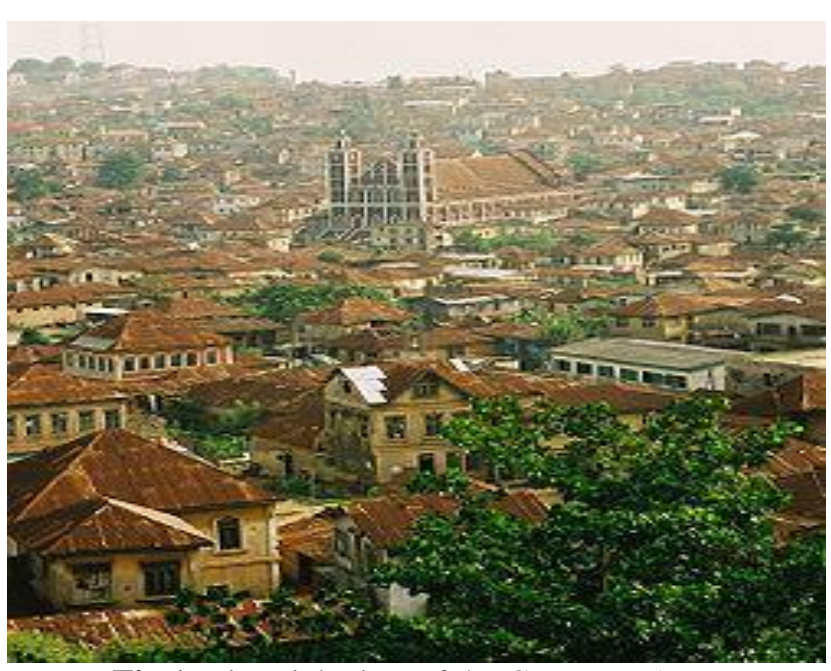

Fig 1: Pictorial View of the Coverage Area

\subsection{Drive Test Survey Routes}

Drive test routes were planned to include all the roads which are covered by different sectors of the sites under study. Also, the main streets around the base stations were included. The test routes reached the over-lapping areas of surrounding neighbour cells. This ensures the proper verification of the actual coverage area of the sites and the handover functions. Some of the major roads covered are: M. K. O. Abiola Way; Olabisi Onabanjo Way; Shokenu Way; Presidential Bouleva Road; Abeokuta-Imeko Road; Shagamu-Abeokuta Road and Kobape Road.

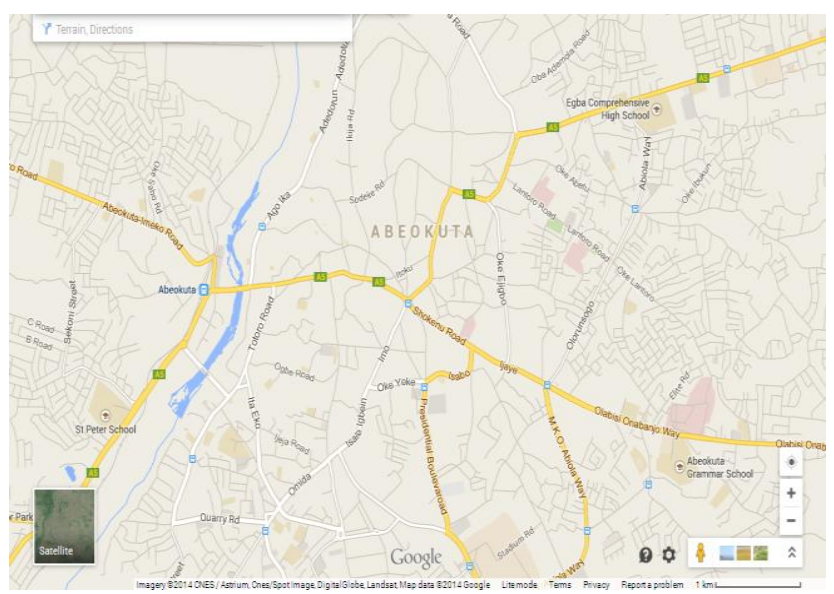

Fig 2: Road Map of the Investigated Area

\subsection{Drive Test Measurement Collection}

A drive test was carried out in dedicated mode to identify the eventual black spots (radio coverage 'holes') present within Abeokuta City, Nigeria. The logs recorded during the drive test were analysed and recommendations were made to improve the radio Quality of Service (QoS) in the city. The test investigated what the mobile users experience on the radio network in the area. This was done by collecting data related to the radio network itself, services running on the network, radio frequency scanner information and geographical positioning data to enable mobile station location logging.
The drive test equipment set-up consists of a laptop, Transmission Evaluation and Monitoring System (TEMS) investigation software (TEMS 9.0), power supply unit, TEMS-enabled test mobile station (Sony Ericsson K800i) with data cable and Universal Serial Bus (USB) hub, Global Positioning System (GPS) and a vehicle. After the base stations data were collected, the drive test was conducted. Short calls and long calls were generated with the test mobile station. The short calls were made to test the accessibility and mobility of the network; while the long calls were made to test the ability of the network to retain and sustain calls set up.

Drive Tests (DT) were conducted in some selected areas. Sites and cells were clearly identified by their identification codes called the Site ID and Cell ID. The detail Site/Cell data configuration is usually called the Cell-Refs. The test involved driving at very low speed along the path of interest, while at the same time placing and monitoring of calls by the Ericsson TEMS phones integrated with Global Positioning system (GPS) for location updates.

The data obtained during the drive test include: received signal strength; neighbouring cell information; GSM radio parameters; frequency band; best server list; signal quality and network events. Interference on Broadcast Control Channel (BCCH) and hopping frequencies were monitored. There were close observations on whether the nearest sector is serving or not. Reasons for call set-up failures were equally noted during the drive test. The post-processing data analysis was carried out with MapInfo Professional software.

\section{RESULTS}

The flexibility of MapInfo Professional software in postprocessing of raw data and the different ways of result presentation offer it a very indispensable tool to network optimization Engineers. The results obtained in terms of received signal level, received signal quality and event handover failure rate were differentiated by colours.

\subsection{Analysis of Radio Network Coverage}

The radio network coverage data obtained from GSM 900 $\mathrm{MHz}$ and Digital Cellular System (DCS) $1800 \mathrm{MHz}$ networks deployed within the city were analysed. This analysis was based on the received signal level, frequency band distribution, best server plan and network coverage statistics.

Figure 3 shows the coverage plot of the received signal level obtainable on the networks at different mobile user locations. The analysis of this result revealed that approximately 205,000 measurement points were collected during the drive test. The received signal strength of a larger proportion of the measurement points (138,869 points) falls within the range of -85 to $-71 \mathrm{dBm}$. Higher signal level values of -71 to $0 \mathrm{dBm}$ were received at 42,017 mobile station locations. The lowest received signal level range of - 
110 to $-95 \mathrm{dBm}$ was experienced at 572 measurement points within the coverage area.

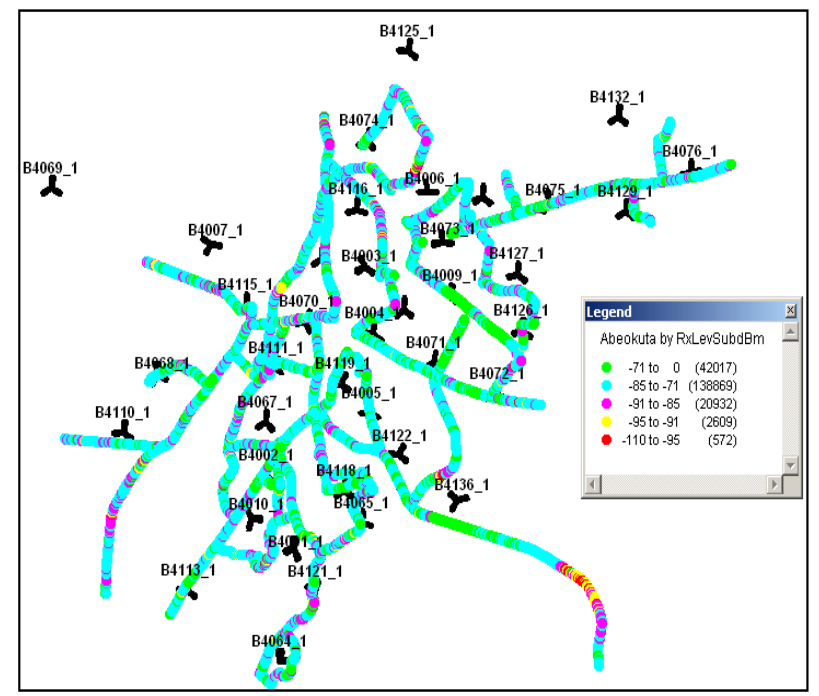

Fig 3: Coverage Plot of Received Signal Level

Figure 4 presents the coverage plot of frequency band distribution of the radio networks deployed within the city under study. The two frequency band investigated were GSM $900 \mathrm{MHz}$ and DCS $1800 \mathrm{MHz}$. The deployed GSM $900 \mathrm{MHz}$ radio network in the city accounted for 7,341 measurement points; while 193,604 measurement points were the contribution of the DCS $1800 \mathrm{MHz}$ radio network technology.

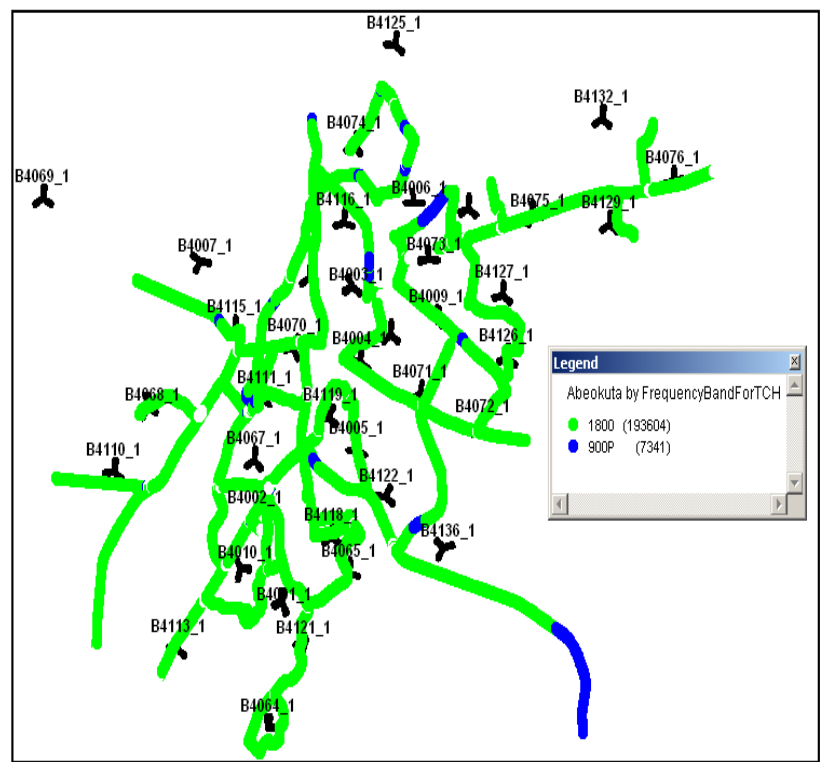

Fig 4: Coverage Plot of Frequency Band Distribution

Figure 5 shows the coverage plot of best server plan of the radio networks investigated. The plot presents the area or locations covered by each cell of the Base Transceiver Stations (BTSs) considered for optimization. The cells were identified by their unique Cell Identity (CI).

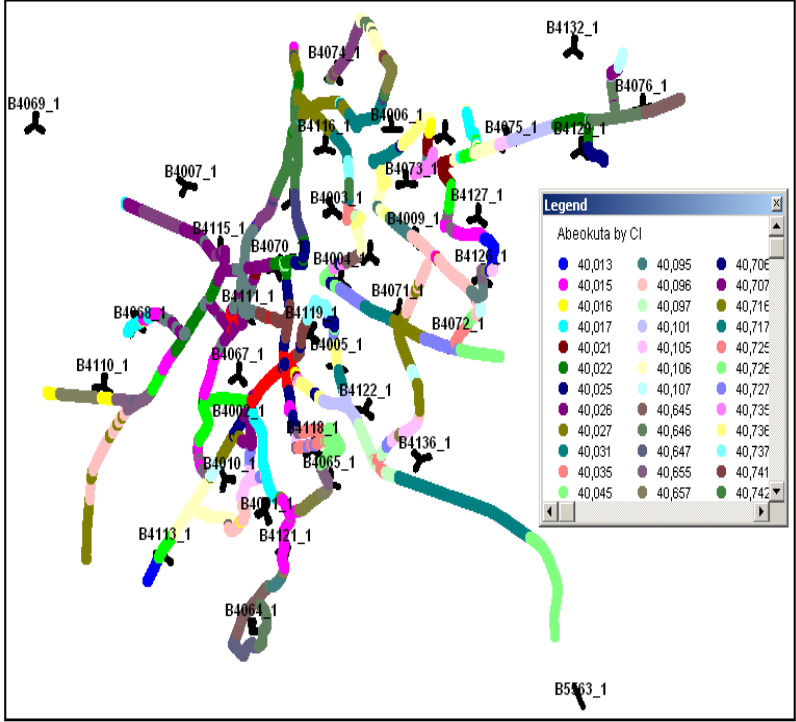

Fig 5: Coverage Plot of Best Server Plan

The GSM radio network coverage statistics are presented in Figure 6. This shows the percentage contribution of different received signal level ranges to the radio network coverage in the Abeokuta City.

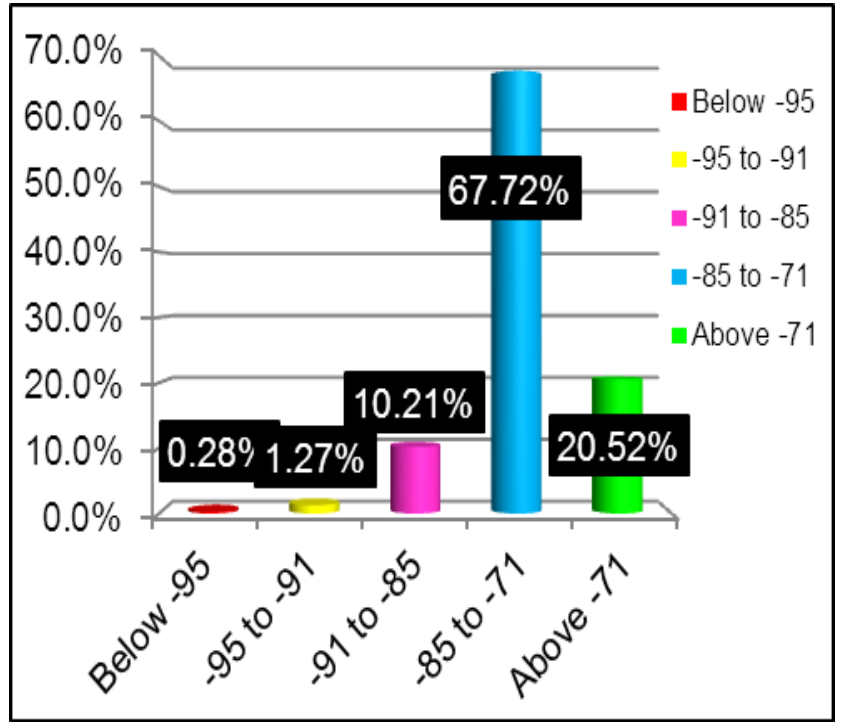

Fig 6: GSM Radio Network Coverage Statistics

Table 1 gives the percentage contribution of the network coverage of each of the radio technologies (GSM $900 \mathrm{MHz}$ and DCS $1800 \mathrm{MHz}$ ) deployed in the city.

Table 1: Coverage Statistics by Frequency Band

\begin{tabular}{|l|l|}
\hline Frequency Band & Contribution (\%) \\
\hline GSM $900 \mathrm{MHz}$ & 3.65 \\
\hline DCS $1800 \mathrm{MHz}$ & 96.35 \\
\hline
\end{tabular}

\subsection{Analysis of Received Signal Quality}

The quality of the radio signal transmitted by the networks was examined. This was achieved by the measure of the received signal quality obtained by TEMS investigation software at different locations as the mobile station moves 
along the test routes. The signal quality of the service offered was assessed by the following radio parameters: received signal quality and Speech Quality Index (SQI).

Figure 7 and Figure 8 show the coverage plots of received radio signal and Speech Quality Index (SQI) respectively.

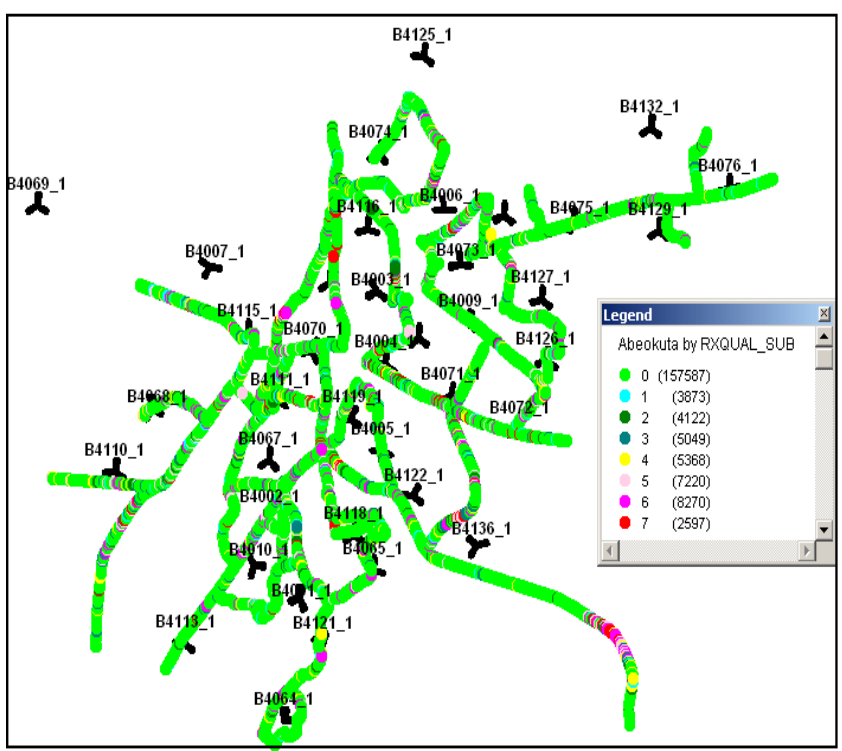

Fig 7: Quality Plot of Received Radio Signal

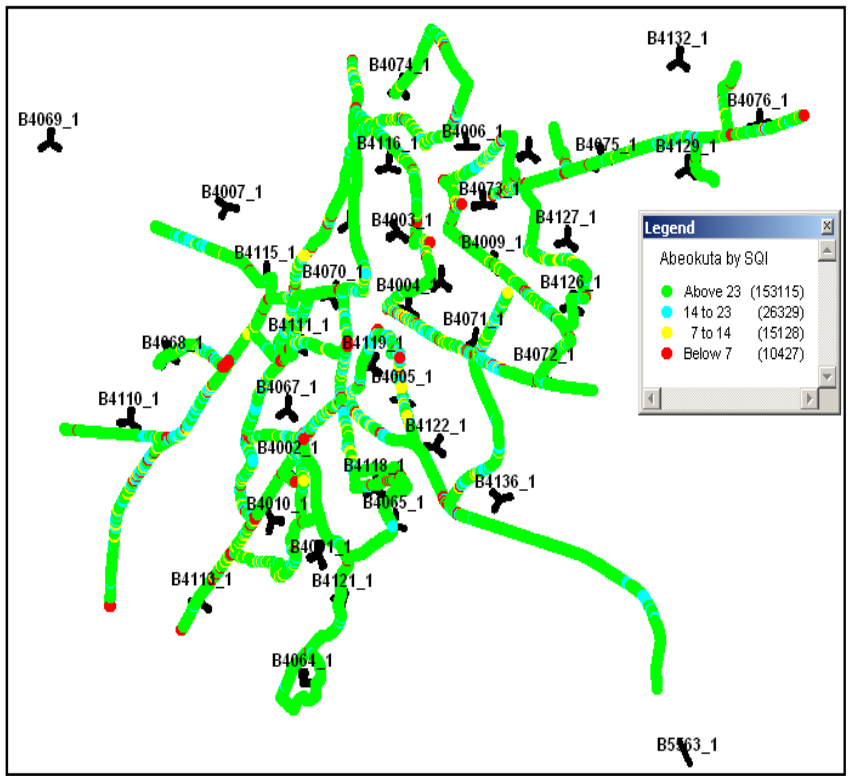

Fig 8: Quality Plot of Received Speech Quality (SQI)

Figure 9 shows the statistics of percentage contribution of each of the signal quality levels ranging from 0 to 7 .

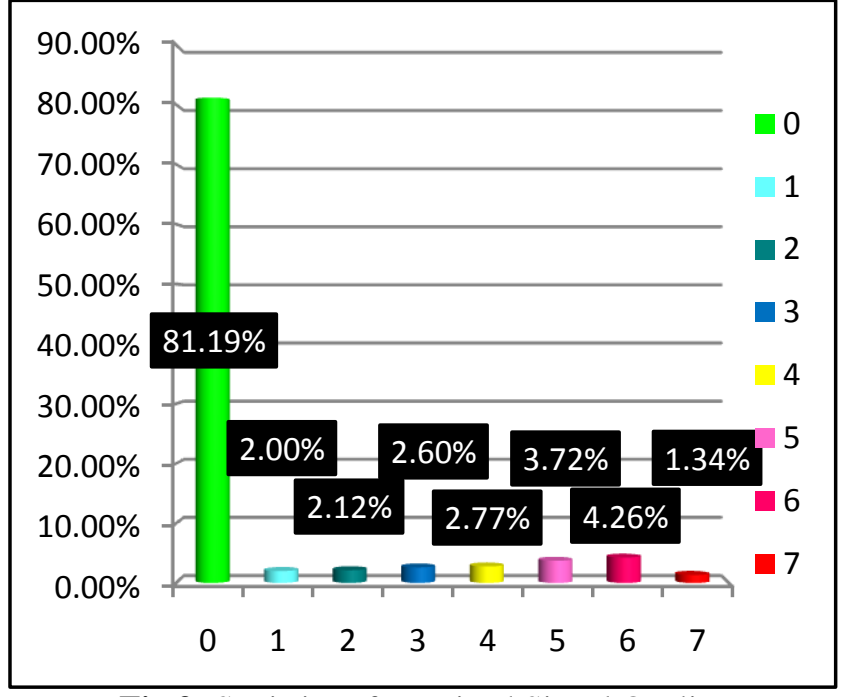

Fig 9: Statistics of Received Signal Quality

Table 2 presents the statistics of percentage contribution of each range of the Signal Quality Index (SQI) with the corresponding remarks.

Table 2: Statistics of Speech Quality Index (SQI)

\begin{tabular}{|l|l|l|}
\hline $\begin{array}{l}\text { Speech Quality Index } \\
\text { (SQI) }\end{array}$ & Remark & $\begin{array}{l}\text { Contribution } \\
(\%)\end{array}$ \\
\hline Above 23 & Excellent & 87.21 \\
\hline 13 to 23 & Good & 7.69 \\
\hline 6 to 13 & Fair & 2.07 \\
\hline Below 6 & Bad & 3.03 \\
\hline
\end{tabular}

\subsection{Analysis of GSM Network Event}

The network events considered in this study are Dropped Calls and the Hand Over (HO) reported during the drive test. There were no dropped calls recorded. Figure 10 shows that there occurred thirty-eight (38) hand over failures in the process.

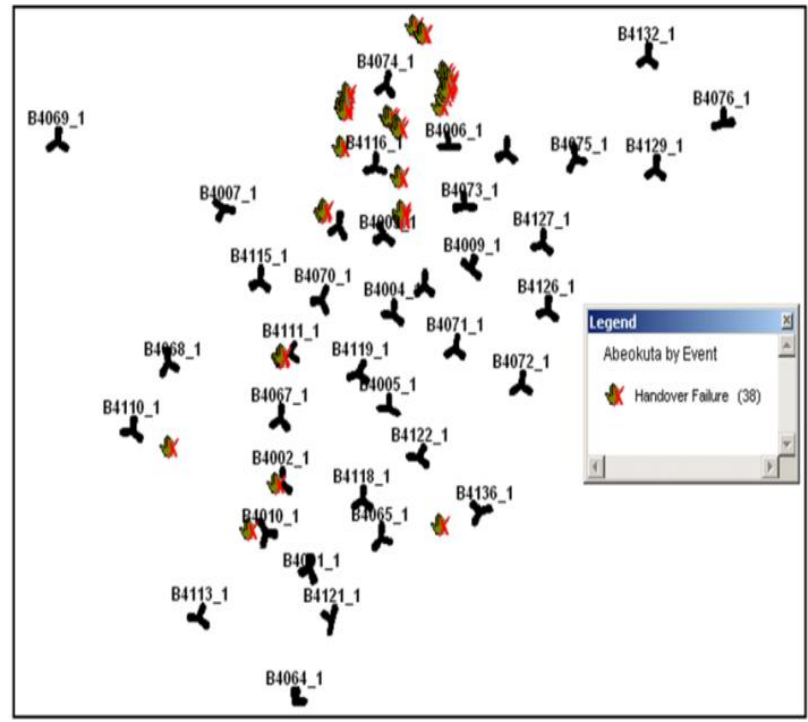

Fig 10: Event Plot of Handover (HO) Failures 


\section{DISCUSSIONS}

The Mobile Station (MS) sensitivity is a component of link budget. This factor is dependent upon the receiver noise figure and minimum level of the Output Signal-to-Noise ratio needed. The recommendation for the MS sensitivity in GSM 900 and DCS 1800 are $-102 \mathrm{dBm}$ and $-100 \mathrm{dBm}$ respectively [6]. The average received signal level experienced in the city is highly satisfactory; about $98.45 \%$ of the total coverage area investigated has received signal level below $-91 \mathrm{dBm}$.

Figure 11 shows significant mobile service degradation experienced along Oke Mosan, Kobape and ShagamuAbeokuta roads. Majority of the 572 measurement points with the lowest received signal level range (-110 to -95 $\mathrm{dBm}$ ) were obtained along these routes. The GSM serving and neighbouring cells list in Figure 12 shows that all available cells are of the received signal level values between $-108 \mathrm{dBm}$ and $-93 \mathrm{dBm}$. Figure 13 displays the GSM radio parameters with poor signal reception at the mobile users end along those routes. With these results, these area experienced severe call drop rate, poor call success rate, event handover failures, and poor traffic streams.

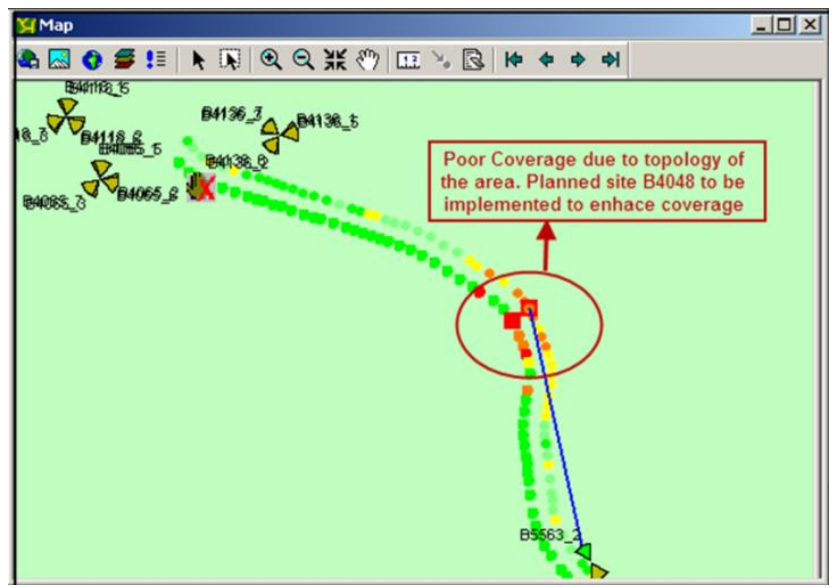

Fig 11: Drive Test Snap Shot of Poor Coverage Area

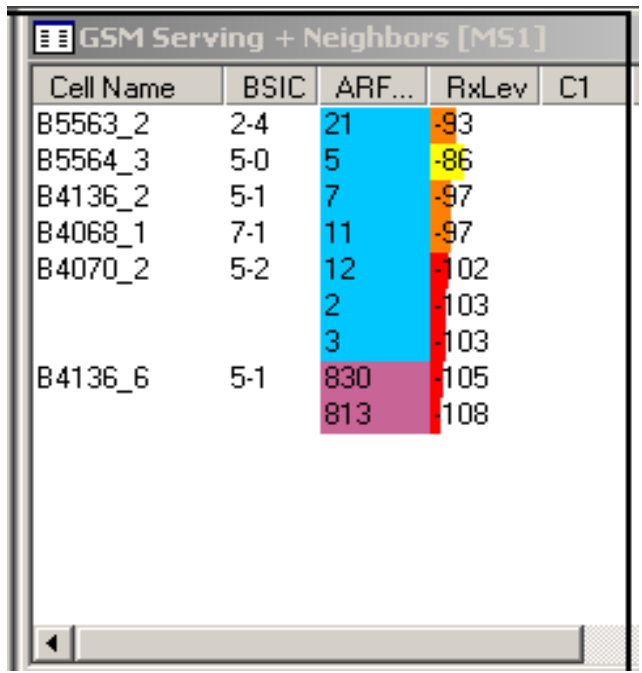

Fig 12: Received Signal Level of Poor Coverage Area

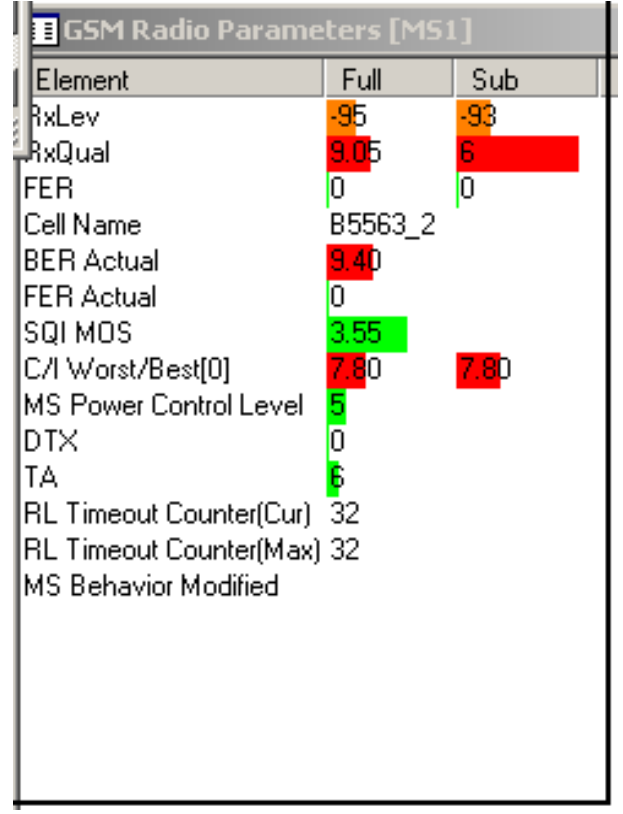

Fig 13: GSM Radio Parameters of Poor Coverage Area

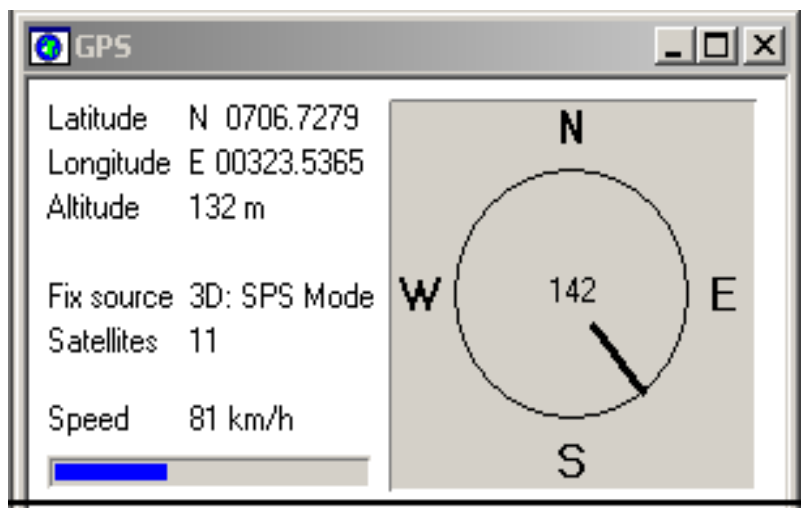

Fig 14: Geographic Information of Poor Coverage Area

The poor coverage encountered along those routes with the geographic information presented in Figure 14 was discovered to be due to the topology of the area as shown in Figure 15.

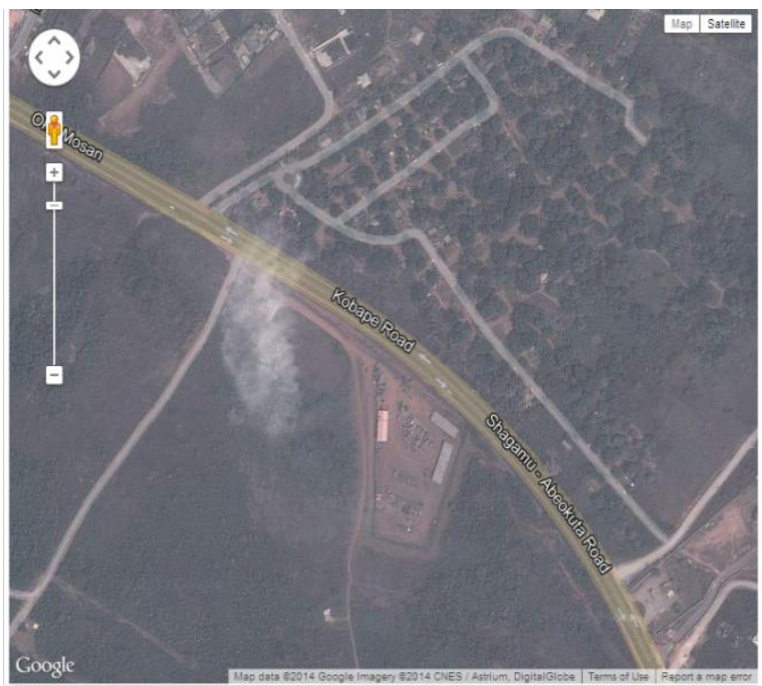

Fig 15: Ariel View of the Poor Coverage Area 


\section{CONCLUSIONS}

This study investigated the network performance and the quality of service delivered by the radio networks of GSM 900 and DCS 1800 deployed in Abeokuta city. The findings of this research work showed that both radio network technologies investigated should be optimized for better quality of service delivery in some parts of the city. The poor radio coverage and degradation in quality of service identified in the affected areas of the city were traced to the land topology and the presence of physical obstructions present in the propagation environment. Also, poor quality samples collected over B5563_2 were due to poor coverage in the area.

We therefore recommend that a base station should be planned by the Radio Network Planning (RNP) team of the network provider and vendor to enhance radio coverage in the affected area. The planned site will also improve the Quality of Service (QoS) offered by the radio networks. The Hand-Over (HO) failures were mainly due to Base Station Controller (BSC) Synchronization issue observed. This should be resolved appropriately and timely. If the optimization is successfully performed, the QoS, reliability and availability of RF Coverage area will be highly improved resulting in more customers and more profits to the mobile telecom service providers.

\section{REFERENCES}

[1]. V. E. Idigo, A. C. O. Azubogu, C. O. Ohaneme and K. A. Akpado, "Real-Time Assessments of QoS of Mobile Cellular Networks in Nigeria", International Journal of Engineering Inventions, Volume 1, Issue 6, pp. 64-68, October, 2012.

[2]. Amaldi, A. Capone, and F. Malucelli, "Radio planning and coverage optimization of $3 \mathrm{G}$ cellular networks", Journal of Wireless Networks, Vol. 14, No. 4, pp. 435-447, August 2008.

[3]. ITU-T E.800, "Definitions of terms related to quality of service", ITU-T Recommendations, E.800 09/2008.

[4]. Patrick O. Olabisi, "Trend Analysis of Key Cellular Network Quality Performance Metrics", International Journal of Engineering Sciences \& Research Technology, 3(7), pp. 916-925, July, 2014.

[5]. Kuhn M. and Prof. Wittneben, "Efficient Quality of Service Measurements in Wireless Mobile Networks," Communication Technology Laboratory, http://www.nari.ee.ethz.ch/wireless/research/projects/tmob.h tml

[6]. Ajay R. Mishra, "Fundamentals of Cellular Network Planning and Optimization 2G/2.5G/3G...Evolution to 4G", John Wiley \& Sons Ltd., 2004.

[7]. ITU-T recommendation G.1000, Communication quality of Service: A framework and definition, 2001.

[8]. Bilal Haider, M. Zafrullah and M. K. Islam, "Radio Frequency Optimization \& QoS Evaluation in Operational GSM Network", Proceedings of the World Congress on Engineering and Computer Science 2009 Vol I WCECS 2009, San Francisco, USA October 20-22, 2009.
[9]. James Agajo, A. L. Theophilus and V. E. Idigo, "Optimization of Network Performance in Wireless Communication Networks", The Pacific Journal of Science and Technology, Volume 13, No. 1, pp. 334-350, May 2012 (Spring).

[10]. Richa Budhiraja and Jitendra Singh Jadon, "Study and Implementation of Drive Test for Development of GSM Network", International Journal of Engineering Trends and Technology (IJETT), Volume 4, Issue 10, pp. 4352-4357, October 2013.

[11]. Wikipedia (2014), "Drive Testing", http://en.wikipedia.org/wiki/Drive_testing.

[12]. J. J. Popoola , I. O. Megbowon, V. S. A. Adeloye, "Performance Evaluation and Improvement on Quality of Service of Global System for Mobile Communications in Nigeria", Vol. 9, No. 2, pp. 91-106, 2009.

[13]. Alexander .N Ndife et al, "Evaluation and Optimization of Quality of Service (QoS) of Mobile Cellular Networks in Nigeria", International Journal of Information and Communication Technology Research, Volume 3 No. 9, Sep-Oct 2013.

[14]. Ugwoke F.N, et al, "Using Software Engineering Approach in Mitigating QoS Challenges in Mobile Communication Networks in Nigeria", Computing, Information Systems, Development Informatics \& Allied Research Journal, Vol. 5, No. 1, March, 2014

[15]. B.M. Kuboye, B.K. Alese, and O. Fajuyigbe, "Congestion Analysis on the Nigerian Global System for Mobile Communications (GSM) Network", The Pacific Journal of Science and Technology, Volume 10, No. 1, May 2009 (Spring).

[16]. Shoewu, O. and Edeko, F.O, "Outgoing call quality evaluation of GSM network services in Epe, Lagos State", American Journal of Scientific and Industrial Research, AJSIR, 2(3) Pp. 409-417, 2011.

[17]. Chisholm, Hugh, ed. (1911). "Abeokuta". Encyclopædia Britannica 1 (11th ed.). Cambridge University Press. pp. 42-43. 